\title{
Comparative Analysis of Different Local Anesthetic Solutions Available in Market: An In Vitro and Clinical Study
}

\author{
Eisha Imran ${ }^{1, \odot}$ Faisal Moeen ${ }^{1} \quad$ Beenish Abbas ${ }^{2} \quad$ Bakhtawar Yaqoob ${ }^{1}$ Mehreen Wajahat ${ }^{3}$ \\ Quratulain Khan ${ }^{4}$ Zohaib Khurshid ${ }^{5,}{ }^{\odot}$
}

${ }^{1}$ Department of Dental Materials, Islamic International Dental College, Riphah University, Islamabad, Pakistan

${ }^{2}$ Department of Pediatric Dentistry, College of Dentistry,

Foundation University, Islamabad, Pakistan

${ }^{3}$ Department of Science of Dental Materials, Avicenna Dental

College, Lahore, Pakistan

${ }^{4}$ Department of Operative Dentistry and Endodontics, Shifa College

of Dentistry, Shifa Tameer e Millat University, Islamabad, Pakistan

${ }^{5}$ Department of Prosthodontics and Implantology, College of

Dentistry, King Faisal University, Saudi Arabia

\begin{abstract}
Address for correspondence Eisha Imran, BDS, MPhil, Department of Dental Materials, Islamic International Dental College, Riphah University, Islamabad, Pakistan (e-mail: eishaimran@ymail.com).
\end{abstract}

Eur J Dent 2021;15:660-668.

\author{
Abstract \\ Keywords \\ - dental local anesthesia \\ - lidocaine \\ - epinephrine \\ - composition \\ $-\mathrm{pH}$ \\ - efficacy \\ - antibacterial activity \\ and cytotoxicity
}

Objectives This study aimed to evaluate and compare various commercially available local anesthetic solutions.

Materials and Methods A total of 150 commercially available local anesthetic cartridges of similar composition ( $2 \%$ lidocaine with epinephrine $1: 100,000$ ) were randomly collected and divided into 3 groups. The designations of groups were selected from their product names such that each group consisted of 60 cartridges. Group $S$ (Septodont, France) Group M (Medicaine, Korea) and Group H (HD-Caine, Pakistan). The samples were divided into five sub-groups, each consisting of 10 cartridges from each group to investigate each parameter.

Results The acquired data was statistically analyzed and compared (using SPSS version 12). Compositional analysis revealed a non-significant ( $P>0.05)$ difference when the three Groups were compared with standard lidocaine and epinephrine solutions. The mean $\mathrm{pH}$ values of samples from group $\mathrm{S}, \mathrm{M}$, and $\mathrm{H}$ respectively fell within the range of $\mathrm{pH}$ values of commercially available solutions. Non-significant difference in EPT values of Group $S$ and $H$ was found when efficacy was compared $(p=0.3)$, however a significant difference $(p<0.01)$ was observed in contrast to Group M. Anti-bacterial activity was observed in all the group and a non-significant difference in cell viability values of Group $S$ and $M$ was found ( $p=0.6$ ), while the difference was significant in comparison to Group H.

Conclusion Within the limitations of these investigations, it appears that the properties of different manufacturers fall within the recommended ranges as mentioned in literature and do not appear to be statistically different in the variables we have tested. published online May 26, 2021
DOI https://doi.org/

$10.1055 / \mathrm{s}-0041-1727553$ ISSN $1305-7456$
(C) 2021. European Journal of Dentistry.

This is an open access article published by Thieme under the terms of the Creative Commons Attribution-NonDerivative-NonCommercial-License, permitting copying and reproduction so long as the original work is given appropriate credit. Contents may not be used for commercial purposes, or adapted, remixed, transformed or built upon. (https://creativecommons.org/licenses/by-nc-nd/4.0/)

Thieme Medical and Scientific Publishers Pvt. Ltd., A-12, 2nd Floor, Sector 2, Noida-201301 UP, India 


\section{Introduction}

Local anesthesia laid the fundamental foundation for pain regulation in dentistry. The backbone of pain management was founded by William Halsted in 1885 by introducing injectable dental local anesthesia, which reformed dental surgery. ${ }^{1}$ Since the beginning of this revolution, a perceptible advancement in dental anesthesiology has been apparent in the anesthetic solutions used. ${ }^{2}$

Despite multitudinous developments in medical and dental sciences, there are still many local and systemic complications encountered in a clinical setting; pain at the injection site, reduced efficacy, ulceration and induced infection at site of injection are the few local complications. At the same time, toxicity is a major systemic complication encountered. $^{3}$

A practitioner preferably needs to have a requisite understanding concerning composition, $\mathrm{pH}$, efficacy, antibacterial activity and cytotoxicity of different anesthetic solutions available to avoid these postoperative complications.

In recent years, different techniques have been proposed to mollify the intensity of pain during the process of injecting an anesthetic. One of these is to use buffered solutions of local anesthesia as recommended in a Cochrane study. Adding a buffer-like bicarbonate with lidocaine increases the $\mathrm{pH}$ of the anesthetic solution, thus reducing the pain during the injection. Pain is ascribed with local anesthetic's acidity; hence, practitioners should know about the $\mathrm{pH}$ and presence of bicarbonate ions in the anesthetic solutions used in clinical practice. $^{3,4}$

Attaining profound anesthesia is essential before starting any dental procedure. A dental practitioner has a wide assortment of options in anesthetic solutions. The difference in their efficacy is of paramount importance. Predominantly, all the solutions available in the market are effective and safe, but still numerous failures of these solutions are mentioned in literature and have been reported. ${ }^{3,5}$

Several factors play a role in increasing the efficacy of any local anesthetic agent. The $\mathrm{pH}$ of local anesthetic solutions is an essential parameter to augment its efficacy. Hogen et al demonstrated that the $\mathrm{pH}$ of commercially available local anesthetics in combination with vasoconstrictors is approximately $4.5 .{ }^{6}$ As the $\mathrm{pH}$ reduces, the local anesthetic efficacy is reduced (as in acidic conditions, the number of ionized fractions dominates in the solution as compared with unionized fractions), thus lowering the volume of local anesthesia accessible to obstruct the sodium channels. Inflammatory conditions like abscess, pulpitis, and apical periodontitis result in reducing the success of local anesthetics. In inflamed tissues, as a result of the accumulation of lactic acid and its byproducts, the $\mathrm{pH}$ of the solution drops to 0.5 to 1.0 resulting in acidosis. The $\mathrm{pK}_{\mathrm{a}}$ of commercially available local anesthetics is more than 7.5. ${ }^{7-9}$ Therefore, in acidic conditions local anesthetics will have a diminished membrane permeability, thereby having a reduced efficacy. ${ }^{3,6}$

Complication due to infection is sparse as we use disposable needles in our clinical practice, but it still occurs in many instances. When a needle penetrates through a contaminated tissue, infection augments into deeper tissues. Simultaneously, multiplex bacterial species colonize the oral cavity, the needle injection causes perforation of the mucous membrane, resulting in entry of these colonized bacteria into the tissues. Under these circumstances, "suppurative local infections or odontogenic bacteremia" may result after using these anesthetic solutions. Ideally, local anesthetic solutions should have superior antimicrobial properties; thus, there is a need to examine the antimicrobial activity of commercially available local anesthetics in the market and conclude if antibiotic prophylaxis is still needed. ${ }^{3,10}$

When toxic concentrations of anesthetic solution diffuse from the blood into the central nervous system, systemic complications develop such as toxicity. In vitro studies signify toxic adverse effects of these drugs on different tissues such as fibroblast, corneal endothelial cells, human leukocytes, and articular chondrocytes.,11-14 Lidocaine, an amide anesthetic, reported numerous adverse effects when used in combination with different vasoconstrictors and preservatives. Epinephrine, a common vasoconstrictor used in combination with various anesthetic agents is reported to cause complications such as necrosis, ischemia, palpitations, or even dysrhythmias. ${ }^{15,16}$

Due to an increase in the prevalence of chemical differences in the similar composition of anesthetic solutions and introduction of newer locally made solutions in the global market by different manufacturers, practitioners should use solutions that are standardized and strictly meet Food and Drug Administration (FDA) requirements. The prospect of this in vitro and clinical study was to assess local anesthetic formulations from three different countries and compare them in terms of composition, $\mathrm{pH}$, efficacy, antibacterial activity, and cytotoxicity.

\section{Materials and Methods}

\section{Sampling}

Three different commercially available local anesthetic solutions (2\% lidocaine and 1:100,000 epinephrine) were obtained. These were Septodont (Saint-Maur-des, France, Lot number 002277), Medicaine (Huons Co.Ltd Gyeonggi-do, Korean, Republic, Lot number GA8127) and HD-Caine (Synchro Pharmaceuticals, Kot-Lakhpat, Lahore, Pakistan, Lot number D-1903). These were labeled as S, M, and H, respectively. A total of 150 samples of each solution were taken. These were further divided into subgroups, each containing 10 samples each for separate testing of composition, $\mathrm{pH}$, efficacy, antibacterial activity, and cytotoxicity.

\section{The Setting of the Study}

Ethical approval for this study was taken from the institutional review committee of Islamic International Dental College (Ref. no. IIDC/IRC/2020/06/007). The study was performed at Caraway Pharmaceuticals (Islamabad, Pakistan), Armed Forces Bone Marrow Transplant center (Islamabad, Pakistan) and Islamic International Dental 
College (Islamabad, Pakistan), from July to September 2020. The study was divided into two stages: in vitro and clinical.

\section{Compositional Analysis}

The high-pressure liquid chromatography (HPLC) (Shimadzu, Japan 20AT) was used for compositional analysis of the local anesthetic solutions. An ultraviolet-visible spectrophotometry (UV-VIS) detector was used for the analysis of lidocaine and epinephrine. An Agilent 120 series HPLC system was utilized to conduct this HPLC-UV analysis. An autosampler, column oven, binary pump, and a degasser (Agilent Technologies, Palo Alto, California, United States) were incorporated in the system. C18 column ( $4.6 \times 150 \mathrm{~mm}, 4 \mu \mathrm{m}$, YMC Co. Ltd., Kyoto, Japan) was used, and the sample solution was injected into it. The flow rate was $1.0 \mathrm{~mL} / \mathrm{min}$, while the temperature of the column was maintained to $30^{\circ} \mathrm{C}$. Chemstation software (Agilent Technologies, California, United States) was used to operate this HPLC system. A standard solution was prepared to be used as a gold yardstick against which the composition of S, M, and $\mathrm{H}$ were compared.

\section{Preparation of Standard Solutions}

Standard solution of lidocaine and epinephrine were prepared by dissolving aliquots of these solutions with mobile phase to yield solutions with final concentrations of $36 \mathrm{mg}$ for lidocaine and $0.02 \mathrm{mg}$ for epinephrine. The concentrations of these internal standards are similar to the concentration of compounds in the cartridge.

\section{Lidocaine Analysis}

Lidocaine detection was performed using reversed-phase HPLC analysis equipped with a C18 column (4.6 × $150 \mathrm{~mm}$, $4 \mu \mathrm{m}$,). The temperature was kept constant at $25^{\circ} \mathrm{C}$ while the $\mathrm{pH}$ was maintained to 5.8 by using $\mathrm{NaOH}$. A combination of methanol and sodium dihydrogen phosphate was incorporated for the mobile phase. The wavelength was adjusted to $230 \mathrm{~nm}$ for UV detection. The flow rate of the sample was kept at $1.0 \mathrm{~mL} / \mathrm{min}$ and $10 \mu \mathrm{L}$ volume was used in the sample injection. The retention time for lidocaine was 9.97 minutes. $^{17}$

\section{Epinephrine Analysis}

Epinephrine detection was performed by using reversedphase HPLC analysis using a C18 column $(4.61 \times 50 \mathrm{~mm}$, $4 \mu \mathrm{m}$,). Temperature and $\mathrm{pH}$ were maintained at $25^{\circ} \mathrm{C}$ and 3.1, respectively. For the mobile phase, a combination of water, methanol, and acetic acid was used. The wavelength was adjusted to $230 \mathrm{~nm}$ for UV detection. The retention time for epinephrine was 2.74 minutes. $^{18}$

\section{Calculation of Results}

The area under the curve was used to determine the concentration of lidocaine and epinephrine in the samples according to the formula given below. ${ }^{19}$

$$
\begin{aligned}
& \text { The concentration } \\
& \text { of sample }
\end{aligned}=\frac{\text { Area of sample }}{\text { area of standard }} \times \begin{aligned}
& \text { Concentration } \\
& \text { of standard }
\end{aligned}
$$

\section{$\mathrm{pH}$}

Each group comprising 10 cartridges was used to measure the $\mathrm{pH}$ of the samples using InoLab $\mathrm{pH}$ meter. In total, $3.6 \mathrm{~mL}$ of anesthetic solution was poured into a beaker and the electrode of the meter was dipped into it and held for a few minutes.

\section{Efficacy, the Clinical Arm of the Study}

A double-blinded, quasi-clinical trial was performed to distinguish and compare the pulpal anesthesia achieved after administering buccal infiltration in the mandibular first molar.

To estimate a mean difference in electric pulp tester (EPT) scores of 13.0 , with a study power of $80 \%$ at a $5 \%$ significance level, a sample size of 11 participants per group was calculated. ${ }^{20}$ Since we had three groups, the sample size for our study was estimated to be 33 .

\section{Screening of the Patients}

Patients diagnosed with irreversible pulpitis $(n=33)$ visiting the operative department for root canal treatment were selected. Informed consent was signed by the participants before the trial. The procedure and any potential risk or benefits were explained to the patients.

A detailed medical history was taken and vitals were recorded. The following inclusion and exclusion criteria were determined:

\section{Inclusion Criteria}

- Male and Female patients between the age range of 18 to 45 years

- Active pain on visual analog scale (>54 mm) A range between 54 and $144 \mathrm{~mm}$ on a Heft-Parker visual analog scale represents mild-to-moderate pain., ${ }^{21,22}$

- The patient felt a sharp localized pain when a cold stimulus (ethyl chloride sprayed on cotton) was applied for 15 seconds on the buccal surface of the tooth ${ }^{23,24}$

- Periapical radiographs revealed the absence of periapical radiolucency

- Vital coronal pulp

\section{Exclusion Criteria}

- Patients with a previous history of allergic reactions to local anesthetics

- Any pathology present near the tooth-like abscess

- Presence of any systemic disease according to American Society of Anesthesiologists (ASA) physical status classification $^{25}$

- Patients who took medication like relaxants or analgesics within 24 hours of injecting the local anesthetic ${ }^{26}$

- History of trauma and smoking (a potential confounder)

\section{Investigational Phase}

The label of the manufacturer was covered by an assistant to assure blinding so that the dentist (one who administered the local anesthesia), and the patient were completely unaware of the formulation that was being administered to avoid biases. Same volume $(1.8 \mathrm{~mL})$ of local anesthetic solution was administered in the buccal fold of mandibular first 
molar by the same dentist so there was no biasness in the injecting technique either. A 30-gauge short needle was used, and the solution was injected steadily. After 10 minutes, a cold test was performed on the patients. Patients with a negative response to cold test were included in the study to ensure that buccal infiltration was successful. Anesthetic efficacy was evaluated by using a commercially available EPT (Denjoy). A rubber dam was placed on the tooth to be tested and was completely dried with cotton wool, and then an acetate strip was placed between the contacts. A small quantity of toothpaste was placed on the tip of the tester as a conducting medium between the tooth and the tester. Next, the tip was placed in middle one-third of the buccal surface. The electrode was placed on the lip to complete the circuit, and the readings were taken 10 minutes after administrating the local anesthetic solution. Patients were asked to respond by raising their hand when they felt any kind of tingling sensation. Two consecutive values of 80 units showed that a profound pulpal anesthesia was achieved. ${ }^{26}$

\section{Antibacterial Activity}

Tryptic soy agar (TSA) plates were used to culture and purify five different bacterial strains as shown is - Table $\mathbf{1}$. These cultures were attained from stock cultures of the biotechnology department of Quaid-e-Azam University, Islamabad, Pakistan. A Negative Control $(0.9 \%$ Sterile Saline) $(\mathrm{NaCl})$ (Grow-cells, United States) and a Positive Control $(20 \mathrm{~mL}$ ampicillin sodium salt; Gibco, Grand Island, New York, United States) were also acquired. Antibacterial was investigated by using a broth dilution method. The bacterial strains were inoculated in a tube of tryptic soy broth (TSB). The turbidity index was set to McFarland standard $10^{5}$ organisms per $\mathrm{mL}$ by using a UV/VIS spectrophotometer (SAILAB, AY 1708008, AE-S90MD). About $2 \mathrm{~mL}$ of all the three anesthetic formulations along with the control solutions were poured into the test tubes and then added $1 \mathrm{~mL}$ of broth culture into each. The calibration of the dilution loop was set to $0.01 \mathrm{~mL}$ and the samples were streaked onto TSA agar plates. The plates

Table 1 Types of bacterial strains used in the study

\begin{tabular}{|l|}
\hline Bacterial strains \\
\hline Staphylococcus aureus (ATCC 6538) \\
\hline Pseudomonas aeruginosa (ATCC 9721) \\
\hline Klebsiella pneumoniae (ATCC 4619) \\
\hline Bacillus subtilis (ATCC 6633) \\
\hline Staphylococcus epidermidis (ATCC 1228) \\
\hline
\end{tabular}

were then placed in an incubator for 24 hours at $37^{\circ} \mathrm{C}$. Next day, the number of bacterial colonies formed were counted manually. ${ }^{27}$

\section{Cytotoxicity Assay}

Mesenchymal Stem Cells (MSCs) of a 24-year-old male were collected from the repository of Air Force Bone Marrow Transplant Center (Islamabad, Pakistan). About $500 \mathrm{~mL}$ of Dulbecco's modified Eagle's medium (DMEM), and 10\% fetal bovine serum were used for cell culturing along with $200 \mathrm{~mL}$ of heparin. $\mathrm{CO}_{2}$ incubator was utilized for cell expansion, which was done over a period of 5 days. On the sixth day, the cultured cells were exposed to $0.25 \mathrm{~mL}$ sample solutions (group S, M, and $\mathrm{H}$ ) along with control solution (Dulbecco's phosphate buffer saline Solution [DPBS]; Gibco, Denmark) for 1 hour, after which the nonadherent cells were centrifuged to remove the nonadherent cells. For complete removal of the local anesthesia, the cells were cleaned with DPBS and were again cultured and kept for 24 hours. Next day, 7-aminoactinomycin D (AAD) stain was utilized to determine cell viability. The centrifuging machine was set at $660 \mathrm{G} / 8 \mathrm{~min}$, and Eppendorf tubes with cell cultures were centrifuged. Next, cell cultures along with $2 \mu \mathrm{L}$ of 7-AAD stain were added in fluorescence-activated cell sorting tube and flow cytometry was done by using a (Navios; Beckman Counter). ${ }^{27}$

\section{Statistical Analysis}

Data was analyzed by using the Statistical Package for Social Science (SPSS for Windows version 12, SPSS Inc., Chicago, Illinois, United States). Mean values ( \pm standard error) for various study attributes, that is, compositional analysis, pH, EPT scores, antibacterial activity, and cytotoxicity were calculated. The magnitude of variation between three groups, that is, $\mathrm{S}, \mathrm{M}$, and $\mathrm{H}$ was ascertained through ANOVA, using completely randomized design (Snedecor and Cochran 1989). Duncan's multiple range test was implied as a post hoc test to detect differences between mean values (Duncan 1955). A $p$-value of 0.05 was arbitrarily considered to be significant.

\section{Results}

\section{Compositional Analysis}

HPLC analysis for the comparative evaluation of composition revealed peaks of standard and sample solutions. - Table 2 gives description of peaks obtained from the curve of HPLC when the standard and sample solutions were tested.

Table 2 High-pressure liquid chromatography results for standard and sample solutions (S, M, and H)

\begin{tabular}{|l|l|l|l|l|l|l|l|l|}
\hline \multirow{2}{*}{ Results } & \multicolumn{4}{l}{ Lidocaine } & \multicolumn{3}{l|}{ Epinephrine } \\
\cline { 2 - 10 } & Standard & Septodont & Medicaine & HD-Caine & Standard & Septodont & Medicaine & HD-Caine \\
\hline Retention time/min & 9.97 & 9.97 & 9.97 & 9.97 & 2.74 & 2.74 & 2.74 & 2.74 \\
\hline Area of curve & 8185478 & 8392210 & 8295329 & 8199829 & 24981 & 25987 & 31889 & 31054 \\
\hline Height of curve & 262731 & 278431 & 262731 & 262731 & 184317 & 2659 & 194427 & 2459 \\
\hline Wavelength/nm & $230 \mathrm{~nm}$ & $230 \mathrm{~nm}$ & $230 \mathrm{~nm}$ & $230 \mathrm{~nm}$ & $230 \mathrm{~nm}$ & $230 \mathrm{~nm}$ & $230 \mathrm{~nm}$ & $230 \mathrm{~nm}$ \\
\hline
\end{tabular}


There was no difference in the lidocaine and epinephrine concentration between the control solution and any of the local anesthetic solutions ( $p>0.05$ ). Also, no difference was found in the lidocaine and epinephrine concentration between any of the three solutions $\mathrm{S}, \mathrm{M}$, or $\mathrm{H}(p>0.05)$, as illustrated in $\mathbf{- T a b l e s} \mathbf{3}$ and $\mathbf{4}$.

\section{$\mathrm{pH}$}

The $\mathrm{pH}$ of $\mathrm{S}(5.30 \pm 0.002)$ was found to be significantly greater than the $\mathrm{pH}$ of both $\mathrm{M}(3.00 \pm 0.002, p<0.01)$ and $\mathrm{H}(4.7 \pm 0.003, p<0.05)$. $\mathrm{H}$ also had a significantly higher $\mathrm{pH}$ than $\mathrm{M}(p<0.01$; - Tables 3 and 4$)$.

\section{Efficacy}

The results of efficacy obtained by EPT before and 10 minutes after administration of local anesthetic solutions indicated that there was no difference in the mean EPT values between Septodont (25.7 \pm 0.7$)$, Medicaine $(25.6 \pm 1.0)$ and HD-Caine $(25.6 \pm 0.8)$ recorded before the injection of the administration $(p<0.05)$. The EPT values 10 minutes after administering the injection were different ( - Table 3 ). $S$ was found to have the highest efficacy $(80.00 \pm 0.00)$. This was followed by $\mathrm{H}$ with an efficacy of $78.80 \pm 0.40$. However, the difference in efficacy between $\mathrm{S}$ and $\mathrm{H}$ was not significant $(p=0.38)$. The efficacy of $\mathrm{M}(70.60+0.90)$ was significantly lesser than both $\mathrm{S}(p<0.01)$ and $\mathrm{H}(p<0.01)$.

\section{Antibacterial Activity}

The highest number of bacterial colonies were formed when bacterial cultures were exposed to group $\mathrm{S}$ followed by group $\mathrm{M}$ and the least by Group $\mathrm{H}$ as illustrated in - Fig. 1 . Therefore, demonstrating the highest antibacterial potential by group $\mathrm{H}$ and the least by group $\mathrm{S}$. The details are given in - Tables 3 and $4 .{ }^{27}$

\section{Cytotoxicity}

The highest percentage viability was observed in the control group followed by group $\mathrm{S}$ and $\mathrm{M}$, while group $\mathrm{H}$ revealed the lowest viability of MSCs as illustrated in - Fig. 2. A nonsignificant difference was observed when the MSCs were exposed to Septodont and Medicaine, while the difference was significant when exposed to HD-Caine and control solution, - Tables 3 and $\mathbf{4}$ gives the details of viability percentages along with their $p$-values. ${ }^{27}$

\section{Discussion}

This contradistinction study of different brands of anesthetic formulations was conducted by analyzing the variance in their composition, pH, efficacy, antimicrobial properties, and cytotoxicity, thus justifying their safe use. The study was conducted independently without any form of financial or otherwise assistance from any of the product manufacturers, hence free from any form of bias.

Several investigations seen in literature have adduced the significance of using HPLC for the quantitative determination of amide linked local anesthetics and catecholamines in pharmaceutical preparations..$^{18,28,29}$ Our study used
HPLC to analyze the differences between the compositions of the three dental anesthetics (Septodont, Medicaine, and HD-Caine) when compared with the standard solutions. The outcome was evaluated by comparing the area under the curve of the samples with the standard solutions. The concentrations of the lidocaine and epinephrine standard solutions were $36 \mathrm{mg}(2 \%)$ and $0.02 \mathrm{mg}(0.001 \%$ or $1: 100,000)$ respectively. Our results suggested that there was no difference between the control solution's concentrations and any of the three solutions ( $\mathrm{S}, \mathrm{M}$, and $\mathrm{H}$ ). These results were in line with the manufacturers' claims.

A similar study was conducted by Salman et al in 2017. They analyzed and compared the concentration of lidocaine HCL by HPLC using a UV detector at a wavelength of $254 \mathrm{~nm}$ at $25^{\circ} \mathrm{C}$ with a retention time of 19 minutes. They concluded that this methodology offered easy and reliable results while utilizing a modest budget. ${ }^{28}$ In another study, Mishra et al determined the concentration of epinephrine by HPLC. They conducted the investigation using UV detector at a wavelength of $280 \mathrm{~nm}$ with a retention time of 3.32 and 3.76 minutes. The results of his experiment revealed the concentration of epinephrine to be $0.988 \mathrm{mg} / \mathrm{mL}$ while the manufacturer claim was $1 \mathrm{mg} / \mathrm{mL}$. This novel finding suggested that this methodology could be routinely performed for the determination of epinephrine in injections. ${ }^{18}$

The results of our study in terms of the $\mathrm{pH}$ of commercially available dental anesthetic solutions are consistent with previous findings. All of the intergroup differences in $\mathrm{pH}$ were found to be significant $(p<0.01)$. However, the range of these findings fell between the values of previous findings by Hogan, Malamad, Mark, and Jason, which state that the normal physiological $\mathrm{pH}$ of commercially available local anesthetics with vasoconstrictors is between 3 to $5 ., 30$ To increase the shelf-life and escalate stability of anesthetic solutions, pharmaceutical companies ensure that the solution's $\mathrm{pH}$ is acidic. At a physiological $\mathrm{pH}$ of 7.4, adrenaline is unstable and thus requires an acidic environment to remain stable. Moreover, in an alkaline medium, lipid-soluble molecules diffuse out due to the low water solubility. ${ }^{8}$ Acidic, water-soluble ionized molecules are present in dental cartridges, and these molecules need to dissociate hydrogen ions in-order to become unionized. After this conversion, the anesthetic solution can infiltrate the nerve sheath and block the sodium gated channels, thereby preventing the generation of an action potential. Furthermore, Shyamala et al stated that using agents with high $\mathrm{pH}$ can increase the anesthetic efficacy as less time is taken by the body for unionized to ionized conversion. ${ }^{6}$ The aromatic ring in the structure of a local anesthetic determines their potency which depends on their lipid solubility. Lipid solubility increases the rate of diffusion through cell membrane, so the proportion of anesthetic solution which is in lipid soluble state determine their onset. Hydrochloric acid is added in the dental cartridges to stabilize the solution, thus making molecules of anesthetic in a water-soluble state while administering the injection. These water-soluble molecules need to be converted to a lipid-soluble structure in order to facilitate diffusion into tissues having a physiologic $\mathrm{pH}$ of 7.4 which is considerably 


\begin{tabular}{|c|c|c|c|c|c|c|c|c|c|c|c|c|c|c|}
\hline & 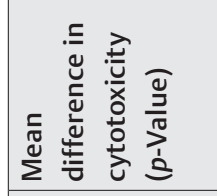 & & & & $\begin{array}{l}0 \\
0 \\
0 \\
0 \\
0 \\
0 \\
+1 \\
+1 \\
0\end{array}$ & $\begin{array}{l}0 \\
0 \\
0 \\
0 \\
0 \\
0 \\
+1 \\
0 \\
0 \\
0\end{array}$ & $\begin{array}{l}0 \\
0 \\
0 \\
\vdots \\
0 \\
+1 \\
0 \\
0 \\
0 \\
0\end{array}$ & 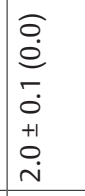 & 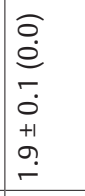 & 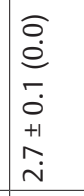 & & & & \\
\hline & 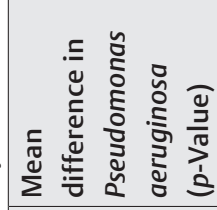 & & & & 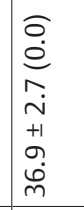 & $\begin{array}{l}a \\
\dot{a} \\
\dot{e} \\
\dot{a} \\
\dot{1} \\
+1 \\
\dot{y} \\
\dot{y} \\
\end{array}$ & 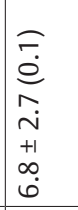 & $\begin{array}{l}a \\
0 \\
0 \\
i \\
i \\
+1 \\
+ \\
\dot{0} \\
\end{array}$ & 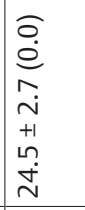 & 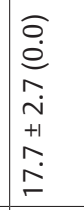 & 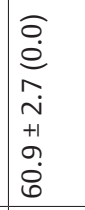 & $\begin{array}{l}a \\
\stackrel{0}{c} \\
i \\
i \\
i \\
+1 \\
0 \\
0 \\
0 \\
0\end{array}$ & $\begin{array}{l}o \\
0 \\
0 \\
0 \\
i \\
i \\
+1 \\
\dot{0} \\
\dot{0} \\
m\end{array}$ & 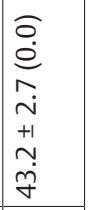 \\
\hline & 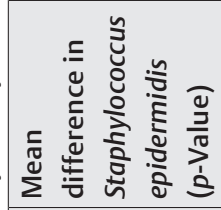 & & & & 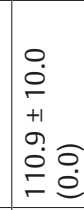 & 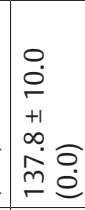 & 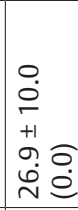 & $\begin{array}{l}0 \\
\dot{0} \\
++1 \\
m \\
\dot{o} 0 \\
\dot{0} \\
i \\
\dot{0}\end{array}$ & $\begin{array}{l}0 \\
0 \\
0 \\
+1 \\
+ \\
\dot{0} \\
\stackrel{0}{0} \\
\stackrel{0}{0}\end{array}$ & 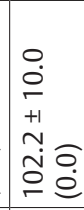 & 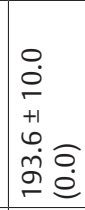 & $\begin{array}{l}0 \\
\dot{0} \\
+1 \\
+1 \\
\hat{i} 0 \\
\dot{q} 0\end{array}$ & 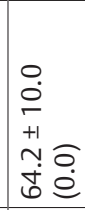 & 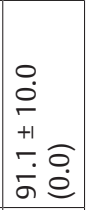 \\
\hline & 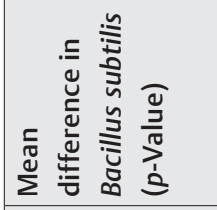 & & & & 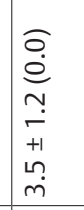 & 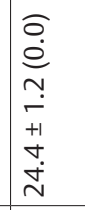 & 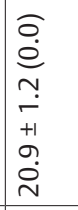 & 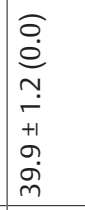 & 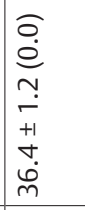 & 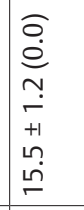 & 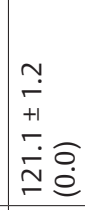 & 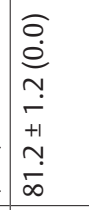 & 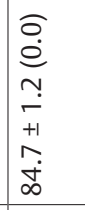 & 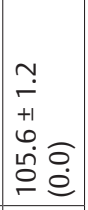 \\
\hline & 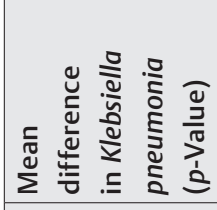 & & & & $\begin{array}{l}0 \\
0 \\
0 \\
0 \\
0 \\
0 \\
+1 \\
m \\
m \\
i \\
i n\end{array}$ & $\begin{array}{l}0 \\
0 \\
0 \\
0 \\
0 \\
0 \\
+1 \\
0 \\
0 \\
0\end{array}$ & $\begin{array}{l}0 \\
0 \\
0 \\
0 \\
0 \\
0 \\
+1 \\
\infty \\
\dot{+} \\
\dot{0}\end{array}$ & $\begin{array}{l}0 \\
0 \\
0 \\
0 \\
0 \\
0 \\
+1 \\
0 \\
0 \\
0\end{array}$ & $\begin{array}{l}0 \\
0 \\
0 \\
0 \\
0 \\
0 \\
+1 \\
0 \\
0 \\
\\
\end{array}$ & $\begin{array}{l}0 \\
0 \\
0 \\
0 \\
0 \\
0 \\
+1 \\
0 \\
0 \\
0\end{array}$ & $\begin{array}{l}0 \\
0 \\
0 \\
0 \\
0 \\
0 \\
+1 \\
0 \\
\text { in } \\
\text { in }\end{array}$ & $\begin{array}{l}0 \\
0 \\
0 \\
0 \\
0 \\
+1 \\
+1 \\
\dot{q} \\
\end{array}$ & 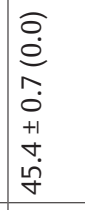 & $\begin{array}{l}0 \\
0 \\
0 \\
i \\
0 \\
0 \\
+1 \\
i \\
0 \\
i n \\
\end{array}$ \\
\hline & 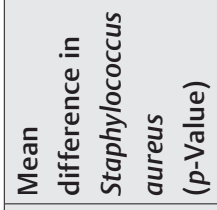 & & & & $\begin{array}{l}\widehat{n} \\
0 \\
0 \\
0 \\
r \\
+1 \\
+1 \\
0 \\
m \\
n \\
\end{array}$ & 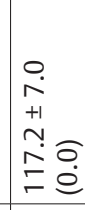 & 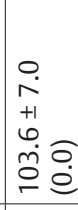 & 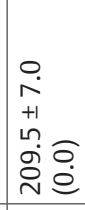 & 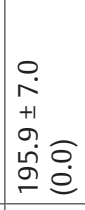 & 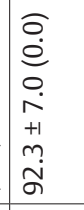 & 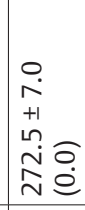 & $\begin{array}{l}0 \\
0 \\
0 \\
0 \\
0 \\
+1 \\
0 \\
0 \\
0 \\
0\end{array}$ & $\begin{array}{l}0 \\
0 \\
0 \\
0 \\
0 \\
1 \\
+1 \\
0 \\
0 \\
0 \\
\end{array}$ & 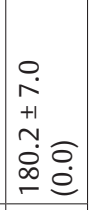 \\
\hline & 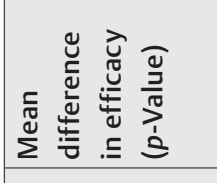 & & & & $\begin{array}{l}0 \\
0 \\
0 \\
0 \\
+1 \\
0 \\
\dot{0} \\
0 \\
0\end{array}$ & 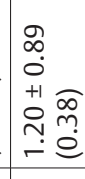 & 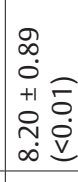 & & & & & & & \\
\hline & 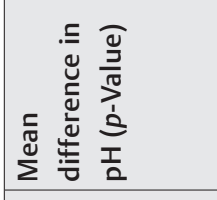 & & & & 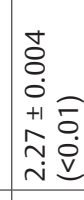 & $\begin{array}{l}0 \\
0 \\
0 \\
0 \\
+1 \\
1 \\
1 \\
0 \\
0 \\
0 \\
0\end{array}$ & 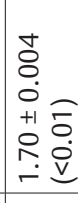 & & & & & & & \\
\hline & 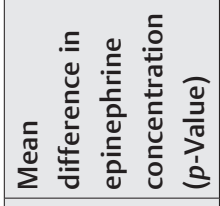 & $\begin{array}{l}m \\
0 \\
0 \\
+1 \\
+ \\
\dot{8} \\
0 \\
0 \\
0\end{array}$ & 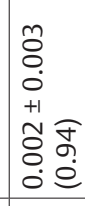 & $\begin{array}{l}m \\
\tilde{\delta} \\
0 \\
+1 \\
m \\
\tilde{\delta} \\
\dot{0} \\
\dot{0} \\
\dot{0}\end{array}$ & $\begin{array}{l}m \\
8 \\
0 \\
0 \\
+1 \\
m \\
0 \\
0 \\
0 \\
0\end{array}$ & 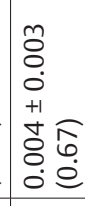 & $\begin{array}{l}m \\
0 \\
0 \\
+1 \\
\dot{0} \\
\dot{8} \\
0 \\
0\end{array}$ & & & & & & & \\
\hline & 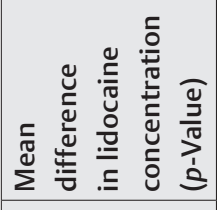 & $\begin{array}{l}0 \\
0 \\
0 \\
+1 \\
+1 \\
\pm \\
0 \\
0 \\
0\end{array}$ & 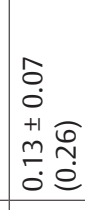 & $\begin{array}{l}\hat{0} \\
0 \\
+1 \\
\text { a } \\
0.9 \\
0 \\
0\end{array}$ & $\begin{array}{l}0 \\
0 \\
0 \\
+1 \\
\vdots \\
0 \\
0 \\
0\end{array}$ & 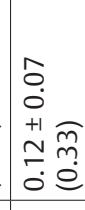 & $\begin{array}{l}0 \\
0 \\
0 \\
+1 \\
\mp \\
\mp \\
0 \\
0\end{array}$ & & & & & & & \\
\hline & 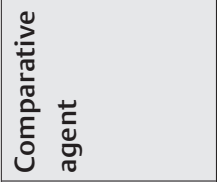 & 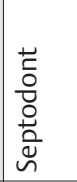 & 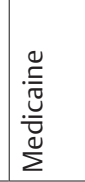 & 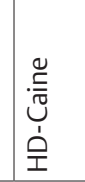 & 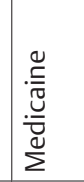 & 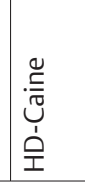 & 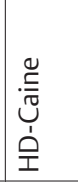 & 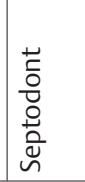 & 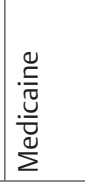 & 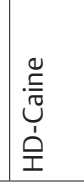 & 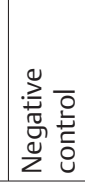 & 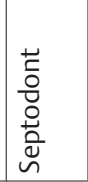 & 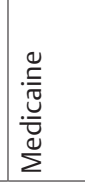 & 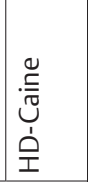 \\
\hline & 离 & 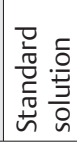 & & & 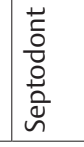 & & 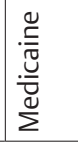 & 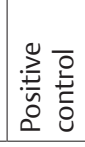 & & & & 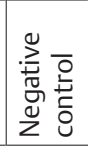 & & \\
\hline
\end{tabular}


Table 4 Mean values for compositional analysis, pH, efficacy, antibacterial activity, and cytotoxicity

\begin{tabular}{|c|c|c|c|c|c|c|}
\hline & Septodont & Medicaine & HD-Caine & $\begin{array}{l}\text { Standard } \\
\text { solution }\end{array}$ & $\begin{array}{l}\text { Positive } \\
\text { control }\end{array}$ & $\begin{array}{l}\text { Negative } \\
\text { control }\end{array}$ \\
\hline Lidocaine concentration & $36.14 \pm 0.08$ & $36.13 \pm 0.04$ & $36.02 \pm 0.01$ & $36.00 \pm 0.00$ & & \\
\hline Epinephrine concentration & $0.021 \pm 0.00$ & $0.018 \pm 0.00$ & $0.017 \pm 0.00$ & $0.020 \pm 0.00$ & & \\
\hline $\mathrm{pH}$ & $5.3 \pm 0.002^{\mathrm{a}}$ & $3.0 \pm 0.002^{b}$ & $4.7 \pm 0.003^{c}$ & & & \\
\hline Efficacy & $80.0 \pm 0.0^{\mathrm{a}}$ & $70.6 \pm 0.9^{b}$ & $78.8 \pm 0.4^{\mathrm{a}}$ & & & \\
\hline Staphylococcus aureus & $209.5 \pm 31.0^{\mathrm{a}}$ & $195.9 \pm 1.7^{a}$ & $92.3 \pm 3.2^{b}$ & & $0^{c}$ & $272.5 \pm 10.3^{d}$ \\
\hline Klebsiella pneumonia & $16.9 \pm 0.5^{\mathrm{a}}$ & $11.6 \pm 0.6^{b}$ & $6.8 \pm 0.2^{c}$ & & $0^{\mathrm{d}}$ & $57.0 \pm 0.0^{\mathrm{e}}$ \\
\hline Bacillus subtilis & $39.9 \pm 0.9^{\mathrm{a}}$ & $36.4 \pm 1.2^{\mathrm{a}}$ & $15.5 \pm 0.5^{\mathrm{b}}$ & & $0^{c}$ & $121.1 \pm 1.2^{\mathrm{d}}$ \\
\hline Staphylococcus epidermidis & $240.3 \pm 15.5^{a}$ & $129.4 \pm 0.9^{b}$ & $102.5 \pm 2.0^{\mathrm{b}}$ & & $0^{c}$ & $193.6 \pm 2.5^{d}$ \\
\hline Pseudomonas aeruginosa & $61.4 \pm 3.0^{\mathrm{a}}$ & $24.5 \pm 1.5^{b}$ & $17.7 \pm 1.5^{b}$ & & $0^{c}$ & $60.9 \pm 2.0^{\mathrm{a}}$ \\
\hline Cytotoxicity & $94.5 \pm 0.1^{\mathrm{a}}$ & $94.7 \pm 0.0^{\mathrm{a}}$ & $93.9 \pm 0.0^{\mathrm{b}}$ & & $96.6 \pm 0.0^{c}$ & \\
\hline
\end{tabular}

Note: $a, b, c$ and $d$ within rows with different superscript letters differ at $P \leq 0.05$.

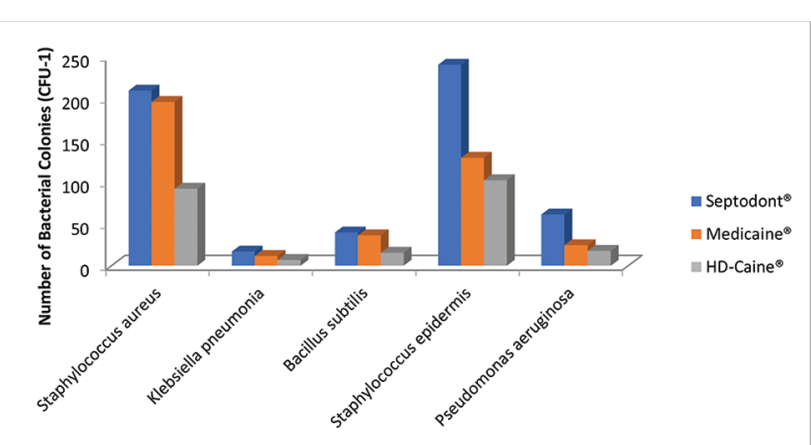

Fig. 1 Comparative mean ( \pm standard deviation) values of the number of bacterial colonies for five bacterial species tested for group $\mathrm{S}, \mathrm{M}$, and $\mathrm{H}$.

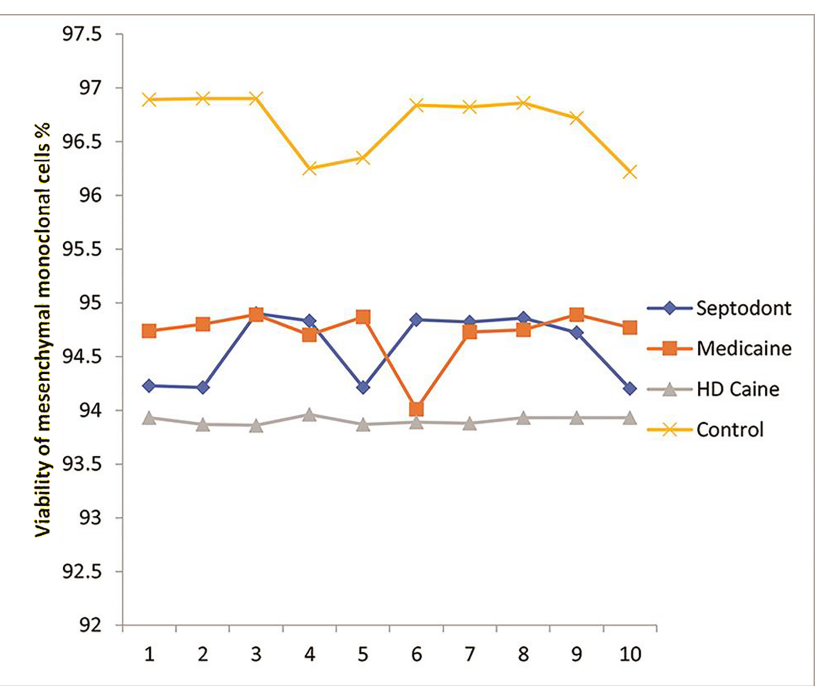

Fig. 2 Viability of mesenchymal monolayer cells for group S, M, and $\mathrm{H}$ as compared with control.

lower than the $\mathrm{pK}_{\mathrm{a}}$ of anesthetics resulting in delayed onset of action. This explains the fact that why there are more chances of local anesthetic failure in infectious cases like abscess as these pathologies create an acidic environment resulting in metabolic acidosis, thus lowering the $\mathrm{pH}$ of the tissues even below 7.4. .,31 $^{-1}$

Painless anesthesia is a major challenge for a dentist as this may cause an unpleasant incident for a patient therefore discouraging them from seeking further treatments especially pediatric dental patients. Consequentially, such patients prefer going for general anesthesia either through IV or gaseous induction to reduce the distress associated with the treatment. ${ }^{32}$ Moreover, various behavior management techniques are also considered. ${ }^{33}$ Ghazal et al conducted a randomized control trial and emphasized on the value and use of visual information during dental procedure. ${ }^{34}$ Studies have proved that pain while injecting the anesthetic is due to the acidity of anesthetic solution along with other factors and thus various clinical studies are focusing on the use of sodium bicarbonate in the solution to raise the $\mathrm{pH}$ more than the physiological $\mathrm{pH}$ of the body. This would also make the anesthetic agent more lipid-soluble. ${ }^{35}$

Local anesthetic efficacy is a multifarious matter, attained by several factors. The study design was plotted to compare the anesthetic efficacy of the three brands of anesthetic solutions commonly used in local market. The results observed in our study were found in accordance with previous studies. The EPT values for all the three groups increased with time after administrating the local anesthetic injection. ${ }^{26}$ The EPT values for $\mathrm{M}$ recorded 10 minutes after the injection was significantly lower than the values recorded for both $\mathrm{S}$ and $\mathrm{H}$.

A similar study was performed by Abdul-Wahab and Boynes, which reported that the mean increase in EPT reading for $2 \%$ lidocaine with 1:100,000 epinephrine was $43.5 \%$. Participants achieved profound pulpal anesthesia in 8 minutes when compared with other formulations (but with different anesthetic agents). They further evaluated soft-tissue numbness, which was achieved between 7 and 15 minutes for all the formulations. ${ }^{26}$ Our study reported a mean increase of $54.3 \%$ for Group S, $45 \%$ for Group M, while Group H showed a mean increase by $53.2 \%$ after 10 minutes. Another study by Meechan et al compared the difference in efficacy achieved on mandibular first molar by buccal infiltration and 
then with a combination of buccal and lingual infiltration using $2 \%$ lidocaine with 1:100,000 epinephrine. Their results showed that the same anesthetic effect was produced either by using buccal infiltration alone or in combination with lingual infiltration in mandibular first molar. Moreover, it took 10 to 14 minutes to achieve peak anesthetic effect when EPT readings were recorded. ${ }^{36}$ Literature reports that to attain an efficacious pulpal anesthesia in cases of irreversible pulpitis, an inferior alveolar nerve block is not always an effective technique; therefore, different techniques should also be considered. ${ }^{37}$

In a venture to analyze and determine a supercilious and suitable local anesthetic brand, this study might help the clinicians to know the relative efficacy and what to expect. In the case of clinical implication, using different local anesthetic agents such as articaine may give superior results. ${ }^{38}$ In this study, since the composition and concentration of cartridges was same, any differences observed in efficacy might have due to the slight differences reported for $\mathrm{pH}$. A trend correlating $\mathrm{pH}$ with efficacy was observed in the study. As the acidity decreased, the efficacy also decreased as shown by group $\mathrm{M}$.

Antibacterial activity of anesthetics is a governing factor to inhibit infections and therefore can serve as prophylaxis before a surgical procedure. Bacteremia, a condition caused by the entry of numerous oral-microflora into the bloodstream, develops when a local anesthetic injection damages the tissue at the point where its injected. ${ }^{39}$ Postoperative dental procedures may supervene infections and injection abscesses, refraining a patient's healing process. Although these complications are infrequent, they do transpire at various instances. They might emanate as a consequence of primary infection when blood circulates from that site and when a contaminated needle penetrates into deeper tissues or it might also be due to negligence of the dentist. ${ }^{3,40}$ The quest of investigating the antibacterial activity of the three pharmaceutical solutions was done to evaluate the most supercilious brand of anesthetic solution that can be used to treat infections or as an irrigant. The findings of our study knot well with the findings of Kesici et al and Aydin et al, the former demonstrated a synergistic antibacterial effect of lidocaine, when used in combination with epinephrine ${ }^{41}$ while the latter reported highest antibacterial activity of lidocaine in contrast to other anesthetic agents. ${ }^{42}$

Our pharmaceutical industry has evolved over recent years. Drugs have different cytotoxic receptors; some destroy the cell membrane or irreversibly bind with receptors while others inhibit protein synthesis. Investigation of cell death by these damages necessitate the use of cell viability assays which are established on diverse cell functions. ${ }^{43}$ Cytotoxic analysis for the three groups revealed a statistically nonsignificant difference between group $\mathrm{S}$ and $\mathrm{M}$. While in comparison to these two groups, group $\mathrm{H}$ and control revealed a significant difference. The findings of our study corroborated with the findings of $\mathrm{Wu}$ et al, who concluded negligible toxic effects of lidocaine in contrast to other anesthetic agents. ${ }^{44}$ Shoshani et al deduced no percentage decrease in adipocyte viability when the cells were exposed to different local anesthetic agents. ${ }^{45}$ Clinical implications of a toxic anesthetic agent increase the likelihood of getting oral paresthesia, ${ }^{46,47}$ muscular stiffness ${ }^{48}$ and palatal ulceration. ${ }^{49}$

\section{Limitations}

This study had its limitations as well. Confounding factors such as any underlying pathologies, operator technique or speed of injecting the solution and the fact affirming the difficulties in achieving pulpal anesthesia in patients with pulpal pathologies were not studied. Dentists need to apprehend these findings and then utilize them in dental practice.

\section{Conclusion}

The composition of lidocaine and epinephrine were same as claimed by the manufacturers. The $\mathrm{pH}$ of the three groups was significantly different; however, the range fell within the $\mathrm{pH}$ of what the manufactures claim. The efficacies of Septodont and HD-Caine anesthetic formulations were ideal.

Investigation of the stability of anesthetic solutions after forced degradation/aging and to check for degradation products using HPLC is highly recommended for future research. Furthermore, the evaluation of change in $\mathrm{pH}$ by the addition of bicarbonate ions, and the possible correlation with reduction in pain during injection would have been an advantage.

\section{Funding \\ None.}

\section{Conflict of Interest}

None declared.

\section{References}

1 Malamed SF. Local anesthetics: dentistry's most important drugs, clinical update 2006. J Calif Dent Assoc 2006;34(12): 971-976

2 Ribeiro PD Jr, Sanches MG, Okamoto T. Comparative analysis of tissue reactions to anesthetic solutions: histological analysis in subcutaneous tissue of rats. Anesth Prog 2003;50(4):169-180

3 Yalcin BK, Complications associated with local anesthesia in oral and maxillofacial surgery. Topics Local Anesthetics Intech Open 2019

4 Frank SG, Lalonde DH. How acidic is the lidocaine we are injecting, and how much bicarbonate should we add? Can J Plast Surg 2012;20(2):71-73

5 Brandt RG, Efficacy of local anesthetics in clinical dentistry: a systematic review and meta-analysis. PhD dissertation: University of Michigan: US. 2010;52(6):779-789

6 Aulestia-Viera PV, Braga MM, Borsatti MA. The effect of adjusting the $\mathrm{pH}$ of local anaesthetics in dentistry: a systematic review and meta-analysis. Int Endod J 2018;51(8):862-876

7 Becker DE, Reed KL. Local anesthetics: review of pharmacological considerations. Anesth Prog 2012;59(2):90-101, quiz 102-103

8 Brandis K. Alkalinisation of local anaesthetic solutions. Aust Prescr 2011;34:173-175 doi:10.18773/austprescr.2011.091

9 Mumba JM, Kabambi FK, Ngaka CT. Pharmacology of local anaesthetics and commonly used recipes in clinical practice. Curr Topics Anesthesiol Intech Open2017 doi:10.5772/67048

10 Aydin ON, Eyigor M, Aydin N. Antimicrobial activity of ropivacaine and other local anaesthetics. Eur J Anaesthesiol 2001;18(10):687-694 
11 Fedder C, Beck-Schimmer B, Aguirre J, et al. In vitro exposure of human fibroblasts to local anaesthetics impairs cell growth. Clin Exp Immunol 2010;162(2):280-288

12 Park J, Sutradhar BC, Hong G, Choi SH, Kim G. Comparison of the cytotoxic effects of bupivacaine, lidocaine, and mepivacaine in equine articular chondrocytes. Vet Anaesth Analg 2011;38(2):127-133

13 Goldstein IM, Lind S, Hoffstein S, Weissmann G. Influence of local anesthetics upon human polymorphonuclear leukocyte function in vitro. Reduction of lysosomal enzyme release and superoxide anion production. J Exp Med 1977;146(2):483-494

14 Chang Y-S, Tseng S-Y, Tseng S-H, Wu C-L. Cytotoxicity of lidocaine or bupivacaine on corneal endothelial cells in a rabbit model. Cornea 2006;25(5):590-596

15 Liu W, Yang X, Li C, Mo A. Adverse drug reactions to local anesthetics: a systematic review. Oral Surg Oral Med Oral Pathol Oral Radiol 2013;115(3):319-327

16 Yagiela JA. Adverse drug interactions in dental practice: interactions associated with vasoconstrictors. Part V of a series. J Am Dent Assoc 1999;130(5):701-709

17 Zanon D, Volpato C, Addobbati R, et al. Stability of a novel lidocaine, adrenaline and tetracaine sterile thermosensitive gel: a ready-to-use formulation. Eur J Pharm Sci 2019;136:104962 doi:10.1016/j.ejps.2019.104962

18 Mishra AK, Mishra A, Chattopadhyay P. A reversed-phase high performance liquid chromatographic method for determination of epinephrine in pharmaceutical formulation. Arch Appl Sci Res 2010;2:251-256

19 KupiecT.Quality-controlanalyticalmethods:high-performance liquid chromatography. Int J Pharm Compd 2004;8(3): 223-227

20 Dianat O, Mozayeni MA, Layeghnejad MK, Shojaeian S. The efficacy of supplemental intraseptal and buccal infiltration anesthesia in mandibular molars of patients with symptomatic irreversible pulpitis. Clin Oral Investig 2020;24(3):1281-1286

21 Shantiaee Y, Javaheri S, Movahhedian A, Eslami S, Dianat O. Efficacy of preoperative ibuprofen and meloxicam on the success rate of inferior alveolar nerve block for teeth with irreversible pulpitis. Int Dent J 2017;67(2):85-90

22 Heft MW, Parker SR. An experimental basis for revising the graphic rating scale for pain. Pain 1984;19(2):153-161

23 Jafarzadeh H, Abbott PV. Review of pulp sensibility tests. Part I: general information and thermal tests. Int Endod J 2010;43(9):738-762

24 Jespersen JJ, Hellstein J, Williamson A, Johnson WT, Qian F. Evaluation of dental pulp sensibility tests in a clinical setting. J Endod 2014;40(3):351-354

25 Doyle DJ, Garmon EH. American Society of Anesthesiologists classification (ASA class). StatPearls; 2019

26 Abdulwahab M, Boynes S, Moore P, et al. The efficacy of six local anesthetic formulations used for posterior mandibular buccal infiltration anesthesia. J Am Dent Assoc 2009;140(8): 1018-1024

27 Imran E, Moeen F, Satti H, Rahman L. Investigating the cytotoxic and anti-bacterial activity of commercially available local anesthetics: An in-vitro analysis. J Pak Dent Assoc 2020;29(4):185-192. Doi:10.25301/JPDA.294.185

28 Al-Salman H, Shaker A, Maan A, Hussein HH. Estimation of lidocaine- $\mathrm{HCl}$ in pharmaceutical drugs by HPLC-UV System. Am J PharmTech Res 2017;7:249-3387

29 Fijałek Z, Baczyński E, Piwońska A, Warowna-Grześkiewicz M. Determination of local anaesthetics and their impurities in pharmaceutical preparations using HPLC method with amperometric detection. J Pharm Biomed Anal 2005;37(5):913-918

30 Goodchild JH, Donaldson M. Comparing the $\mathrm{pH}$ change of local anesthetic solutions using two chairside buffering techniques. Compend Contin Educ Dent 2016;37(5):e6-e12
31 Ueno T, Tsuchiya H, Mizogami M, Takakura K. Local anesthetic failure associated with inflammation: verification of the acidosis mechanism and the hypothetic participation of inflammatory peroxynitrite. J Inflamm Res 2008;1:41-48

32 Gazal G, Fareed WM, Zafar MS. Effectiveness of gaseous and intravenous inductions on children's anxiety and distress during extraction of teeth under general anesthesia. Saudi J Anaesth 2015;9(1):33-36

33 Gazal G, Fareed WM, Zafar MS, Al-Samadani KH. Pain and anxiety management for pediatric dental procedures using various combinations of sedative drugs: a review. Saudi Pharm J 2016;24(4):379-385

34 Gazal G, Tola AW, Fareed WM, Alnazzawi AA, Zafar MS A randomized control trial comparing the visual and verbal communication methods for reducing fear and anxiety during tooth extraction. Saudi Dent J 2016;28(2):80-85

35 Kashyap VM, Desai R, Reddy PB, Menon S. Effect of alkalinisation of lignocaine for intraoral nerve block on pain during injection, and speed of onset of anaesthesia. $\mathrm{Br} \mathrm{J}$ Oral Maxillofac Surg 2011;49(8):e72-e75

36 Meechan JG, Kanaa MD, Corbett IP, Steen IN, Whitworth JM. Pulpal anaesthesia for mandibular permanent first molar teeth: a double-blind randomized cross-over trial comparing buccal and buccal plus lingual infiltration injections in volunteers. Int Endod J 2006;39(10):764-769

37 Gazal G, Fareed WM, Zafar MS. Role of intraseptal anesthesia for pain-free dental treatment. Saudi J Anaesth 2016;10(1):81-86

38 Brandt RG, Anderson PF, McDonald NJ, Sohn W, Peters MC. The pulpal anesthetic efficacy of articaine versus lidocaine in dentistry: a meta-analysis. J Am Dent Assoc 2011;142(5):493-504

39 Roberts GJ, Simmons NB, Longhurst P, Hewitt PB. Bacteraemia following local anaesthetic injections in children. $\mathrm{Br}$ Dent J 1998;185(6):295-298

40 Kim HT, Lim S-W, Yim KH, et al. Antibacterial effect of lidocaine in various clinical conditions. Anesth Pain Med 2019;14(2):165-171

41 Kesici S, Demirci M, Kesici U. Antibacterial effects of lidocaine and adrenaline. Int Wound J 2019;16(5):1190-1194

42 Aydin ON, Eyigor M, Aydin N. Antimicrobial activity of ropivacaine and other local anaesthetics. Eur J Anaesthesiol 2001;18(10):687-694

43 Aslantürk ÖS. In Vitro Cytotoxicity and Cell Viability Assays: Principles, Advantages, and Disadvantages, Genotoxicity - A Predictable Risk to Our Actual World, Marcelo L. Larramendy and Sonia Soloneski; IntechOpen. 2017. Doi: 10.5772/intechopen.71923. Available at: https://www.intechopen.com/ books/genotoxicity-a-predictable-risk-to-our-actual-world/ in-vitro-cytotoxicity-and-cell-viability-assays-principles-advantages-and-disadvantages

44 Wu T, Shi Z, Song H, Li Y, Li JH. Cytotoxicity of local anesthetics on rabbit adipose-derived mesenchymal stem cells during early chondrogenic differentiation. Exp Ther Med 2018;16(4):2843-2850

45 Shoshani O, Berger J, Fodor L, et al. The effect of lidocaine and adrenaline on the viability of injected adipose tissue-an experimental study in nude mice. J Drugs Dermatol 2005; 4(3):311-316

46 Garisto GA, Gaffen AS, Lawrence HP, Tenenbaum HC, Haas DA. Occurrence of paresthesia after dental local anesthetic administration in the United States. J Am Dent Assoc 2010;141(7):836-844

47 Ahmad M. The anatomical nature of dental paresthesia: a quick review. Open Dent J 2018;12:155-159

48 Sánchez GA, Takara D, Alonso GL. Local anesthetics inhibit Ca-ATPase in masticatory muscles. J Dent Res 2010;89(4): 372-377

49 Sharma U. Palatal ulceration: a local anesthetic complication. Indian J Health Sci Biomed Res 2017;10(1):94 